\title{
ИССЛЕДОВАНИЕ ПРАВОВЫХ ОСНОВ ОБЕСПЕЧЕНИЯ БЕЗОПАСНОСТИ ПРИ ВЫПОЛНЕНИИ ГЕОДЕЗИЧЕСКИХ, КАДАСТРОВЫХ, ЗЕМЛЕУСТРОИТЕЛЬНЫХ И ИНЫХ РАБОТ В ПОЛЕВЫХ УСЛОВИЯХ
}

\section{Павел Васильевич Мучин}

Сибирский государственный университет геосистем и технологий, 630108, Россия, г. Новосибирск, ул. Плахотного, 10, доцент кафедры техносферной безопасности, тел. (383)344-42-00, e-mail: p.v.muchin@ssga.ru

\section{Максим Павлович Мучин}

Сибирский государственный университет телекоммуникаций и информатики, 630100, Россия, г. Новосибирск, ул. Кирова, 86, обучающийся, тел. (906)195-12-01, e-mail: maxim4521@yandex.ru

Выполнен анализ доступных для ознакомления нормативных правовых актов, локальных нормативных документов и других информационных источников, отражающих вопросы обеспечения безопасности при выполнении полевых геодезических работ. Отмечены недостатки существующей системы по созданию правовых основ, регулирующих вопросы безопасности выполнения различных видов работ с использованием методов геодезии. Показаны возможности СГУГиТ в разработке необходимых нормативных правовых актов.

Ключевые слова: геодезия, безопасность, охрана труда, техника безопасности, нормативные правовые акты

\section{RESEARCH OF LEGAL BASES OF ENSURING SAFETY AT PERFORMANCE OF GEODETIC, CADASTRAL, LAND MANAGEMENT AND OTHER WORKS IN FIELD CONDITIONS}

\section{Pavel V. Muchin}

Siberian State University of Geosystems and Technologies, 10, Plakhotnogo St., Novosibirsk, 630108, Russia, Associate Professor, Department of Technosphere Safety, phone: (383)343-42-00, e-mail: p.v.muchin@ssga.ru

\section{Maxim P. Muchin}

Siberian State University of Telecommunications and Informatics, 86, Kirova St., Novosibirsk, 630100, Russia, Student, phone: (906)195-12-01, e-mail: maxim4521@yandex.ru

The analysis of normative legal acts available for acquaintance, local normative documents and other information sources reflecting questions of safety at performance of field geodetic works is carried out. Shortcomings of the existing system on creation of the legal bases regulating questions of safety of performance of various types of works with use of methods of geodesy are noted. The possibilities SSGA in the development of the necessary normative legal acts.

Keywords: geodesy, safety, labor protection, safety, regulations

В настоящей работе выполнено исследование достаточно актуального, на наш взгляд, вопроса обеспечения нормативными правовыми актами в области безопасности процесса выполнения работ «геодезической направленности». При 
этом, наиболее важной проблемой является обеспечение безопасности выполнения таких работ в полевых условиях. Учитывая, что «полевые условия» при выполнении разного вида работ геодезической направленности могут быть одинаковыми, далее под геодезическими работами будем понимать топографо-геодезические и инженерно-изыскательские работы, кадастровые и землеустроительные работы, маркшейдерские работы и др.

Выполнение камеральных работ, как правило, производиться с использованием ПЭВМ и условно такие работы можно считать как «офисные». Вопросы обеспечения безопасности выполнения офисных работ решены достаточно полно через разработанные и применяемые нормативные правовые акты в области охраны труда, санитарно-гигиенических требований, требований электрои пожаробезопасности. Руководителям организаций, где выполняются камеральные работы, в основном требуется разработать комплект локальных нормативных документов, регулирующих вопросы обеспечения безопасности работников и технологических процессов. Учитывая это, вопросы обеспечения безопасности выполнения камеральных работ в настоящей статье не рассматриваются.

Актуальность проблемы обеспечения безопасности выполнения полевых геодезических работ, авторам очевидна, поскольку постоянно приходится консультировать руководителей «геодезических» организаций по вопросам разработки локальных нормативных актов, подготовки документов для участия в тендерах на получения заказа, расследования несчастных случаев на производстве, обучения и др.

Как было сказано выше, работодатель обеспечивает безопасность, прежде всего, через разработку собственного комплекта локальных нормативных актов в области охраны труда и техники безопасности, электро- и пожаробезопасности, возможно решение вопросов промышленной и экологической безопасности, гражданской обороны и защиты в чрезвычайных ситуациях, соблюдения санитарно-гигиенических требований [1-6]. Локальные нормативные акты разрабатываются с учётом требований законодательных и подзаконных нормативных правовых актов. Важным звеном здесь является нормативно-правовая деятельность федеральных органов исполнительной власти через подготовку соответствующих стандартов, правил и типовых инструкций по охране труда, приказов, распоряжений и др. Очевидно, что при этом создаются правовые основы обеспечения безопасности с учётом отраслевых особенностей деятельности. При полноценной работе соответствующих государственных органов власти, руководители геодезических организаций могли бы самостоятельно выполнить все требования по обеспечению безопасности и разработать необходимые локальные документы.

При подготовке настоящей работы был выполнен поиск в сети интернет доступных для ознакомления документов, определяющих правовые основы обеспечения безопасности выполнения полевых геодезических работ. Результаты исследований существующих правовых основ представлены ниже. 
В настоящее время имеется ряд нормативных правовых актом в области обеспечения безопасности полевых работ, которые разработаны достаточно давно, но формально продолжают действовать. Существует и несколько документов разработанных в последние несколько лет, качество подготовки которых так же рассмотрено в этой работе.

До представления отдельных нормативных правовых актов в области обеспечения безопасности полевых работ, целесообразно отметить, что полнота и качество подготовки соответствующих документов зависит от структуры управления отраслью или, как минимум, государственной организацией выполнения рассматриваемых нами работ. Становиться очевидным, что самый высокий уровень разработки правовых основ обеспечения безопасности при выполнении полевых геодезических работ, был в системе ГУГК при СМ СССР. Отдельные документы того времени продолжают действовать, например «Правила по технике безопасности на топографо-геодезических работах» (ПТБ-88). Настоящие правила были обязательны для всех предприятий, организаций и учреждений ГУГК СССР, выполняющих топографо-геодезические и картографические работы.

Анализируя настоящие «Правила» заметим, что, на наш взгляд, продолжающееся «действие» документа обусловлено не его действительной актуальностью, а тем, что просто ничего подобного до сих пор не разработано. Сами «Правила» устарели не только морально, но и в правовой основе. При этом отметим, что подобный документ, подготовленный с учётом современных требований, чрезвычайно необходим для «геодезических» организаций.

В качестве ещё одного примера работы ГУГК СССР в этом направлении, отметим разработку отраслевого стандарта «Порядок обучения безопасности труда и допуска к работам повышенной опасности в организациях топографогеодезического производства» (ОСТ 68 12.0.05-87). Срок действия стандарта был определён до 01.07.92 г. Очевидна необходимость разработки подобного документа и в наше время.

Позднее определённая работа по созданию правовых основ обеспечения безопасности при выполнении геодезических работ выполнялась Федеральной службой геодезии и картографии России (Роскартография). Среди разработанных нормативных правовых документов отметим:

1. Отраслевой стандарт «Отраслевая система стандартов по безопасности труда. Основные положения» (ОСТ 68-12.0.01-02). Разработанный ЦНИИГАиК в 2002 г. и введённый в действие Приказом по Роскартографии № 136-пр от 06 сентября 2002 г.

Как сказано в преамбуле документа: «Настоящий стандарт устанавливает назначение, структуру и содержание отраслевой системы стандартов по безопасности труда (далее ОССБТ), а также построение, содержание и порядок согласования стандартов этой системы.

Положения настоящего стандарта распространяются на стандарты, направленные на обеспечение безопасности при всех видах работ, выполняемых в системе Роскартографии»; 
2. Руководящий документ «Требования безопасности труда при эксплуатации топографо-геодезической техники и методы их контроля» (РД БГЕИ 36-01). Разработанный и введённый в действие ЦНИИГАиК в 2001 г. Согласованный с Роскартографией 25.12.2000 г. № 4-09-3849;

3. «Инструкция по охране труда при производстве топографо-геодезических работ для нужд земельной реформы и составлению кадастра», утверждённая Приказом Роскартографии от 30.01.1995 г. № 14п.

В документе отражено: «Настоящая инструкция направлена для организации безопасного полевого топографо-геодезического производства. В «Инструкции» изложены общие требования по технике безопасности при производстве топографо-геодезических работ в населенных пунктах и территориях промышленных объектов, требования безопасности при эксплуатации спутниковых приёмоиндикаторов и автомобильного транспорта в полевых условиях, основные условия работы на персональном компьютере, а также правила оказания первой (доврачебной) помощи пострадавшим».

Указанные выше документы, разработанные в Роскартографии, продолжают использоваться и в настоящее время. При этом необходимо отметить несоответствие современным требованиям отраслевого стандарта ОСТ 68-12.0.01-02. А также, например, очевидное несоответствие современным нормативным требованиям «Инструкции по охране труда при производстве топографо-геодезических работ для нужд земельной реформы и составлению кадастра» в части оказания первой помощи, работы с ПЭВМ и др.

Создание при Министерстве экономического развития Российской Федерации Федеральной службы государственной регистрации, кадастра и картографии (Росреестр) вероятно предполагало и дальнейшее развитие на федеральном уровне правовых основ обеспечения безопасности при выполнении полевых «геодезических» работ. К нашему сожалению положительных примеров работы Росреестра в этом направлении мы привести не можем. При этом утверждённые Приказом Росреестра от 30.05.2016 г. № П/0263 «Положения о территориальных органах Федеральной службы государственной регистрации, кадастра и картографии по субъектам Российской Федерации» содержат следующие требования: «Проводить необходимую работу по обеспечению безопасных условий и охраны труда, предупреждению производственного травматизма и профессиональных заболеваний, соблюдению требований законодательства об охране труда, технике безопасности и производственной санитарии, охране государственной собственности и соблюдению правил пожарной безопасности» [7].

Вместе с тем отметим разработку стандарта саморегулируемой организации «Межрегиональный союз кадастровых инженеров» СТО-30845203.41-2016 «Охрана труда и техника безопасности при выполнении кадастровых работ». Настоящий стандарт утверждён 29.06. 2016 г. (протокол № 49). Стандартом установлены требования к охране труда и технике безопасности при выполнении кадастровых работ в полевых и камеральных условиях. Положения стандарта подлежат применению в профессиональной деятельности кадастрового инженера. 
Учитывая, что стандарт СТО-30845203.41-2016 является одним из самых современных документов и, по сути, обязателен для применения при выполнении кадастровых работ, рассмотрим его более внимательно.

Наши замечания:

1. Примерно 20 \% нормативных документов, на которые идут ссылки в стандарте, в настоящее время утратили силу;

2. Применяются понятия и термины по отменённому стандарту;

3. Рассматривается отменённая аттестация рабочих мест по условиям труда вместо уже введённой в 2013 году федеральным законом специальной оценки условий труда;

4. Меры безопасности при выполнении полевых работ взяты в основном из указанных выше «Правил по технике безопасности на топографо-геодезических работах» (ПТБ-88) без какой либо серьёзной актуализации. По сути, термин «топографо-геодезические» работы заменён на «кадастровые» работы. Отмечаем, что при этом не учтены современные природоохранные требования, правовые основы пожарной безопасности, возможности современных средств связи, правовые требования по оказанию первой помощи пострадавшим, действия при несчастном случае и др.

Дополнительно к рассмотренным выше правовым и нормативным документам в области обеспечения безопасности при выполнении полевых геодезических работ следует отметить наличие отдельных документов, разработанных в других отраслях экономики, например свод правил СП 11-104-97 «Инженерногеодезические изыскания для строительства», введённый Госстроем России в 1997 г. и ряд других.

Отмеченные недостатки создания полноценных правовых основ в области обеспечения безопасности выполнения полевых геодезических работ на федеральном (отраслевом) уровне порождают трудности по созданию локальных нормативных документов в этой области на уровне организаций. Исследования показали большое разнообразие в подходе к разработке локальных нормативных документов для организаций (предприятий, учреждений). При этом неизбежны ошибки и неточности.

В заключение отметим, что учитывая требования, определённые в «Положении о разработке, утверждении и изменении нормативных правовых актов, содержащих государственные нормативные требования охраны труда» (утверждённое Постановлением Правительства Российской Федерации от 27.12.2010 г. № 1160) [8], наш университет мог бы выполнить разработку проектов основных нормативных правовых документов в области обеспечения безопасности при выполнении геодезических, кадастровых, землеустроительных, инженерно-геодезических, топографо-геодезических, маркшейдерских и иных работ в полевых условиях.

При этом возможно использование организационного и научного потенциала таких структурных подразделений СГУГиТ как, центра безопасности труда, кафедры техносферной безопасности, кафедры кадастра и территориального планирования и других кафедр.

Заказчиком такой работы могла бы выступить Федеральная служба государственной регистрации, кадастра и картографии. 


\section{БИБЛИОГРАФИЧЕСКИЙ СПИСОК}

1. "Трудовой кодекс Российской Федерации" от 30.12.2001 № 197-ФЗ [Электронный ресурс] - Режим доступа: http://www.consultant.ru/document/cons_doc_LAW_34683/.

2. Федеральный закон "О пожарной безопасности" от 21.12.1994 № 69 -ФЗ [Электронный pecypc] - Режим доступа: http://www.consultant.ru/document/cons_doc_LAW_5438/.

3. Федеральный закон "О санитарно-эпидемиологическом благополучии населения" от 30.03.1999 № 52-Ф3 [Электронный pecypc] - Режим доступа: http://www.consultant.ru/document/cons_doc_LAW_22481/.

4. Федеральный закон "О промышленной безопасности опасных производственных объектов" от 21.07.1997 № 116-ФЗ [Электронный ресурс] - Режим доступа: http://www.consultant.ru/document/cons_doc_LAW_15234/.

5. Федеральный закон "О защите населения и территорий от чрезвычайных ситуаций природного и техногенного характера" от 21.12.1994 № 68-Ф3 [Электронный ресурс] - Режим доступа: http://www.consultant.ru/document/cons_doc_LAW_5295/.

6. Федеральный закон "О гражданской обороне" от $12.02 .1998 \mathrm{~N} 28-Ф 3$ [Электронный pecypc] - Режим доступа: http://www.consultant.ru/document/cons_doc_LAW_17861/.

7. Об утверждении положений о территориальных органах Федеральной службы государственной регистрации, кадастра и картографии по субъектам Российской Федерации. Приказ Росреестра от 30.05.2016 г. № П/0263 [Электронный ресурс] - Режим доступа: http://www.consultant.ru/document/cons_doc_LAW_275796/.

8. Об утверждении «Положения о разработке, утверждении и изменении нормативных правовых актов, содержащих государственные нормативные требования охраны труда». Постановление Правительства Российской Федерации от 27.12.2010 г. № 1160 [Электронный ресурс] - Режим доступа: http://www.consultant.ru/cons/cgi/online.cgi?req=doc\&base=LAW\&n=166736\&fld=134\&dst=100 0000001,0\&rnd $=0.3848369003071208 \# 07580107913395464 /$.

(C) П. В. Мучин, М. П. Мучин, 2021 